


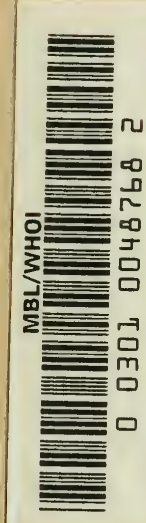





\section{STUDIES IN SPERMATOGENESIS}

WITH ESPECIAL REFERENCE TO THE

\section{"ACCESSORY CHROMOSOME"}

BY N. M. STEVENS.

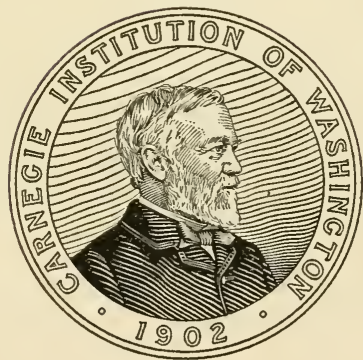

WASHINGTON, D. C. :

Published by the Carnegie Institution of Washington September, 1905. 
CARNEGIE INSTITUTION OF WASHINGTON

PUbliCATION No. 36

$$
3404
$$




\section{STUDIES IN SPERMATOGENESIS WITH ESPECIAL REF- ERENCE TO THE "ACCESSORY CHROMOSOME."}

By N. M. STEVENS.

In connection with the problem of sex determination it has seemed necessary to investigate further the so-called " accessory chromosome," which, according to McClung ('O2), may be a sex determinant. This view has been supported by Sutton ('O2) in his work on Brachystola magna, but rejected by Miss Wallace ('O5) for the spider.

The forms selected for study have been taken from several groups of insects, and are all species whose spermatogenesis has not been previously worked out. They are (I) a California termite, Termopsis angusticollis; (2) a California sand-cricket, Stenopelmatus; (3) the croton-bug, Blattella germanica; (4) the common meal-worm, Tenebrio molitor; and (5) one of the aphids, Aphis cenothere.

A brief account of a chromatin element resembling the accessory chromosome in Sagitta has been added for comparison. The spermatogenesis of each form will be described in detail, and a general discussion of the results and their relation to the accessory chromosome and sex determination will follow. The spermatogenesis of the aphid has been included in another paper, but a summary of results and a few figures will be given here for reference in the general discussion.

\section{METHODS.}

The testes were fixed in various fluids-Flemming's strong solution, Hermann's platino-aceto-osmic, Gilson's mercuro-nitric, Lenhossek's alcoholic sublimate acetic, and corrosive acetic. Flemming's and Hermann's fluids followed by safranin gave good results in most cases. The mercuro-nitric solution and Lenhossek's fluid gave excellent fixation and were preferable to the osmic mixtures when it was desirable to stain the same material with iron-hæmatoxylin, and also with various anilin stains.

Heidenhain's iron-hæmatoxylin, either alone or with orange G or erythrosin, was used more than any other one stain. $\mathrm{W}^{\prime}$ ith osmic fixation safranin gave better results in some cases, because of the 
abundance of spindle fibers and sphere substance which were stained by hæmatoxylin. The safranin-gentian combination used by Miss Wallace and others in the study of the accessory chromosome did not prove to be especially helpful with these forms. Thionin was found to be a very useful stain for distinguishing between the accessory chromosome and an ordinary nucleolus. Licht-grün was often used in combination with safranin.

\section{RESULTS OF INVESTIGATIONS.}

Termopsis angusticollis.

In the termite it was not found to be practicable to dissect out the testes. The tip of the abdomen was therefore fixed and sectioned, young males whose wings were just apparent being used. The cells are all small, and could not be studied to advantage with less than I 500 magnification (Zeiss oil immersion $2 \mathrm{~mm}$, , oc. I2).

In the spermatogonium there is a very large nucleolus (plate I, fig. I), which in the iron-hæmatoxylin preparations is very conspicuous, but does not stain like chromatin with thionin or other anilin stains, nor does it behave like an accessory chromosome during the maturation mitoses. Before each spermatogonial division it divides as in figures 2 and 3 , and the same is true for each maturation mitosis. Figure 4 shows the 52 chromosomes of a spermatogonial division in metaphase. Figures 5 and 6 are young spermatocytes, showing the division of the nucleolus. Figures 8, 9, and ro show a stage immediately following that shown in figure 6 and evidently persisting for some time. The spireme thread is very fine, stains deeply, and is wound into a dense ball, often concealing one (fig. 10) or both nucleoli (fig. 8). Figure I I shows the next stage; the bivalent chromosomes are so disposed as to give the familar " bouquet stage," with the loops directed away from the centrosome and sphere $(c)$. Figures 12, 13, and $\mathrm{I}_{4}$ show the later development of the same stage, the chromatin loops becoming thicker by the concentration of the smaller granules to form the larger ones seen in figure I4. The loops now straighten out and extend in various directions across the nuclear space (figs. 15, I6, I7). In fig. I8 $a$ a longitudinal split is seen in several chromosomes. Figures $18 b, 19,20$, and 21 show various stages in the contraction of these split bivalent chromosomes to form diamond-shaped tetrads, each side of which is a univalent daughter chromosome. The tetrads come into the spindle in this form (figs. 22, 23), and change to the form shown in figure 24 during the metaphase (figs. 22, 26, 28). Figures 25 and 27 show the 26 bivalent chromosomes, or tetrads, in 
early and late metaphase, respectively, and figures 29,30 , and 31 in anaphase. This is certainly a reduction division, for the tetrads are always somewhat elongated and come into the spindle with their longer axes parallel with the axis of the spindle. The aberrant bodies in these figures are probably remains of the nucleoli; they are found only in iron-hæmatoxylin preparations. Figures 31 and 32 show exceptional cases where the cell has divided. Usually the two daughter nuclei are formed in an undivided cell. The resting-stage between the two divisions is only partial. The nucleolus appears and divides into two (figs. 33-36), and the chromosomes change into the dyad form (fig. 36), in which they come into the second maturation spindle (figs. 37,38 ). The equatorial plate again shows 26 chromosomes (fig. 39), The formation of the spermatozoa is peculiar in that the original spermatocyte cell-body, as a rule, does not divide; but the four nuclei resulting from the two maturation divisions develop into sperm-heads in one cell. All have a nucleolus (fig. $4 \mathrm{I}$ ), and in a slightly later stage (fig. 42) the elongated nuclei have a distinct centrosome and sphere at the posterior end. Later stages are shown in figures 43,44 , and 45 .

The points of greatest interest in the spermatogenesis of Termopsis angusticollis are, ( $\mathrm{I}$ ) the fact that no accessory chromosome is present ; (2) that the method of tetrad formation and reduction are clear, despite the fact that the cells and the chromatin elements are quite small; and (3) the failure of the cell-bodies to divide and the consequent development of four spermatozoa in one cell.

\section{Stenopelmatus.}

The spermatogonium of Stenopelmatus contains from one to three large nucleoli, which stain much less with thionin than does the spireme (plate II, figs. $46,47,48$ ). As the distinct chromosomes come into view in the prophase of mitosis, two are seen to be nearly twice as long as the others, but of equal length (figs. $48,49,50$.) There are 46 chromosomes in the equatorial plate of a spermatogonial spindle (fig 50). Besides the nucleolus $(n)$, there appears in the young spermatocyte a conspicuous element $(x)$ which stains deeply with all chromatin stains (fig. 5I). It is closely applied to the nuclear membrane and is connected with an end of the spireme (figs. 51-54). At first it is quite small, and it gradually increases in size during the spireme stage. There is no "bouquet stage" in this form. Figure 55 slows the spireme segmented and split longitudinally. The segments have begun to open out at the center to give the cross which is the typical tetrad form in Stenopelmatus. Figures $56,58,59$, and 60 show various stages in the contraction of the split segments to form crosses and 
diamond-shaped rings. The tetrads usually remain connected by delicate linin threads, as shown in figures 57 and 60, also in figures 62 and 63 , the latter taken from the metaphase of the first maturation spindle. If these linin connections persist, as they appear to do, from the segmentation of the spireme to metakinesis, the first division of the contracted tetrads must be longitudinal, corresponding to the split in the segments of figures $55,57,58$, etc. The chromosomes in the metaphase usually appear as dumbbells (fig. 66) or elongated crosses (fig. 67), but occasionally one can be found which still shows its tetrad nature (fig. 64), so clearly indicated in the quadrivalent crosses of figure 59. In the anaphase the chromosomes are often split as in figure 68 , and occasionally the two components can be seen as plainly as in figure 65 . Figure $6 \mathrm{I}$ shows the various shapes assumed by the element $x$ during the tetrad-stage of the chromosomes. This element $x$ almost invariably appears in a vesicle near one pole of the spindle (figs. 67, 68); in exceptional cases it is found nearer the equatorial plate, as in figure 66 , or even in the same plane with the ordinary chromosomes, but always somewhat isolated from them. In position and form this element resembles the accessory chromosomes described by Baumgartner ('O4) for Gryllus domesticus; in its mode of origin it seems to differ from the other accessory chromosomes yet described.

Figures 69 and 70 show the 23 bivalent chromosomes in metaphase; in figure 69 the element $x$ is shown partly behind the large chromosome and at a different level. In figures 66 and 67 the one exceptionally large chromosome doubtless represents the two larger ones of the spermatogonia. In the anaphase the element $x$ is sometimes as conspicuous as in figure $7 \mathrm{r}$; in other cases it is concealed either behind or within the polar mass of chromatin. In this form there is a distinct resting stage between the two maturation mitoses (figs. 72-75). The element $x$ is conspicuous in one-half of the cells (figs. 72, 73); it may be included in the nucleus as in figure 72 , or it may be partly or wholly outside, as in figures 74,75 , and 76 . In the latter case, but not in the former, it is surrounded by its own membrane. As the chromatin begins to condense for the second mitosis, disintegration of the element $x$ becomes apparent. This is most easily made out in cases where the element is isolated, as in figures 75 and 76 ; but there seems to be little doubt that it disappears before the metaphase of the second maturation mitosis. It is not possible to count the chromosomes in this stage, they are so crowded together, but it is not probable that such a conspicuous chromatin element as that seen in the first division could escape detection, even if it were in the equatorial plate among the chromosomes. No aberrant element is ever seen in these spindles; 
and, moreover, all of the spindles and all of the spermatids appear to be exactly alike at the same stage. The chromosomes are double in the prophase (fig. 77) and always appear double in the equatorial plate (fig. 78), the paired elements corresponding to those of figure 65 .

In figure 80 , plate IIr, a pair of spermatids is shown with nuclear membrane formed and the spindle fibers twisted in a characteristic manner. Figure $8 \mathrm{I}$ is a slightly later stage with the spindle-remains massed against the nuclear membrane. Curiously enuugh there appears in the nucleus of every spermatid a body similar to the element $x$ of the spermatocytes of the first order (figs. 82-86). This body is often applied to the nuclear membrane and connected with the spireme (figs. 84-86). It decreases in size and finally disappears (figs. 88-9I). The spindle-remains divides (fig. 83 ), and a small part of it (a) goes to form the acrosome at the apex of the head (figs. 85-92). The larger part is probably utilized in the formation of the tail, for it gradually disappears as the tail develops.

The centrosome which, although small, is conspicuous in each mitosis, is seen in figure 83 between the two parts of the spindleremains, applied to the outside of the nuclear membrane. In figures 85,86 , and 87 the relation of the tail (or its axial fiber) to the centrosome is shown. In figures 87 and 88 , instead of the small spherical centrosome of figures 83 to 86 , we have a much elongated body, at first (fig. 87) applied for its whole length to the nuclear membrane, but later 1ying along one side of a middle piece $(m)$, as shown in figure 89 , and in a later stage in figures 90 to 92 . The mature spermatozoön with its forked anterior end appears in figure 93.

The points of especial interest in the spermatogenesis of Stenopelmatus are the development of the aberrant chromatin element $x$ during the growth stage of the spermatocyte of the first order, its distribution to one-half of the spermatocytes of the first order, its disappearance during the rest stage between the two maturation divisions, and the development of a similar, though smaller, element in all of the spermatocytes.

\section{Blattella germanica.}

Unlike the spermatogonia of Stenopelmatus, those of Blattella have both a faintly-staining nucleolus and a deeply-staining chromatin element $(x)$, and moreover the two are always closely associated (figs. $95,96)$. The number of chromatin elements in the equatorial plate of late spermatogonial mitoses is 23 (fig. 97). Later events indicate that one of the 23 is the element $x$, but it is impossible to distinguish it here. Figure 98 is a very early stage of the spermatocyte of the first order, showing the element $x$ as a $U$-shaped body. The centrosome 
was also conspicuous in all of the cells of this group. The spireme here, as also in figure 99, is fine and closely interwound. In figure 99 and again in figure roo the element $x$ is joined to the spireme as it is throughout the spireme stage. In the "bouquet" or "polarized" stage the combined nucleolus and element $x$ are always at one side of the group of loops and down very close to the base of the figure (figs. IOI, IO3). In figure IO2 most of the loops are cut across. The stage shown in figures 104 and 105 is a later one than that just described. Here we have again a continuous spireme connected with the element $x$, making it seem improbable that the bivalent chromosomes are really separated in the bouquet stage. Figure 106 gives some of the variations in form of the combined nucleolus and element $x$. The last of the five figures was taken from a giant cell containing at least twice the usual amount of chromatin. In one giant cell four unusually large combinations of this kind were found, and a corresponding amount of chromatin in the spireme. In figure 107 one sees the spireme divided into segments still joined by linin bridges. In figure I08 similar segments may be seen, one of them showing a longitudinal split. The element $x$ is present, but the nucleolus has disappeared. In many cases the split, if it appears at all, closes quickly and the chromosome bends in U-shape, as in figure rog, plate rV. This figure also shows two centrosomes $(c)$. In other cases the split persists as in figure $\mathrm{I}$ Io and leads to the formation of crosses of a tetrad character (figs. III, II2, II3), as in Stenopelmatus and many other insects. Figures II 4 to II 7 show later stages of the $U$-shaped chromosomes. Perfect rings are rare. All sorts of variations are seen, broad and narrow $U$-shapes, rings split at one point or the opposite points, a $U$ split at the bottom (fig. I I 4 ), pairs of parallel rods (fig. I I5), and occasionally rods constricted in the middle and showing a longitudinal split in each half, as in figure I 6 . Figure II 7 shows different views of the split rings. Apparently all of these forms straighten out so that the two components of the bivalent chromosome stand end to end as dumbbells or compressed crosses in the metaphase of the first maturation spindle (figs. I 23-125). The element $x$ remains concentrated and more or less spherical in form. Figures I 8 - 122 are equatorial plates, with $x$ absent in figure $\mathrm{I} 20$, in the same plane as the $\mathrm{I}$ other chromosomes in figure 119 , far to one side in figure 118 , and near one pole of the forming spindle in figure 122 . It is also shown in various positions with regard to the spindle in figures $I 23$ to $I 26$ and $I 28$ to $I 32$. In figure 125 it is apparently double, and again in figure 129 . In figure I 30 one lagging chromosome shows the dyad nature of the products 
of the division of the tetrad. In this form there can be no doubt that reduction occurs in the first spermatocyte division. The element $x$ is very often concealed by the polar aggregation of chromatin, but it is sometimes as conspicuous as in figures $\mathrm{I} 3 \mathrm{I}$ and $\mathrm{I} 32$. The spermatocytes of the second order go into a complete resting stage before they are completely separated, and one of a pair shows the element $x$, while it is lacking in the other (fig. I33). At the close of the resting stage the chromosomes appear as I I pairs of rods of considerable length, which gradually shorten and thicken and usually bend at the center, forming U's or V's (figs. ${ }^{3} 34-138$ ). In one stage these double U's look much like tetrads (fig. I 38 ). The rods straighten again as they shorten still more (fig. I39), become more closely approximated, and finally form dumbbells, as in figure $\mathrm{r} 4 \mathrm{r}$.

The element $x$ is, of course, present in only one-half of these nuclei. In the equatorial plate, figure $\mathrm{I}_{42}$, it is absent ; in figure $\mathrm{I} 43$ it is present, but can not be distinguished from the other chromosomes, while in figure 144 it is rendered conspicuous by its spherical form and isolated position. In only a few cases has it been possible to distinguish $x$ in the spindle. Figures 146 and 147 show two of these cases where this element is clearly double and of different form from the other chromosomes. It is probable that it divides and so goes into one-half of all of the spermatids, as in McClnng's typical cases of the accessory chromosome. Figure 145 shows the usual appearance of the other chromosomes in metaphase. The two spermatids of a pair are always alike so far as any evidence of the presence of the element $x$ is concerned (fig. I48). Figure I 49 is an exceptional case, where one chromatin element (possibly $x$ ) has evidently divided late and been left out in the cytoplasm; a smaller chromatin granule is also present in the cytoplasm of each spermatid. All of the spermatids, as in Stenopelmatus, develop a deeply-staining body, which, however, in this case is usually centrally located and often appears double (figs. I 50-I 52).

The spindle-remains (Spindelreste) forms a very conspicuous body at one side of the nucleus in the spermatids, and occasionally a mass of chromatin, probably due to imperfect mitosis, is found near the spindlesubstance (fig. I50). The mass of spindle-substance at first appears structureless, but soon assumes the condition shown in figures I5o to 152. In one individual many of the spermatids had two balls of spindlematerial (fig. ${ }^{2} 5^{2}$ ), and the resulting later stages were double-tailed (fig. 153). Figure 156 shows how the spindle-substance goes into the tail and gradually disappears as the tail lengthens. 
The centrosome is evidently applied to the nuclear membrane, as in Stenopelmatus, and the middle-piece is developed in connection with it, as in figures $156-157,154-155,158-160$. The element $x$ of the spermatids gradually disappears (figs. I 50, I 59). An acrosome develops at the anterior end, the head condenses and lengthens, and we have the ripe spermatozoön (fig. I6I). The tail is very long and is shown only in part.

Of the forms studied, Blattella alone has many degenerate spermatozoa. Some follicles have none, others a number varying perhaps from one-fourth to three-fourths of the whole number. No evidence of degeneracy was detected among the young spermatids up to the stage shown in figures $154^{-1} 55$, where a few like figure 162 were found. Most of the degenerate forms occur among the nearly ripe spermatozoa or in the sperm-ducts. Such are shown in figures 163 to 168 . The chromatin is strangely broken up into irregular clumps, and probably no two of these degenerate sperm-heads can be found which are alike. The tails are always imperfect. The distribution and varying numbers of these degenerate spermatozoa make it impossible to interpret their condition as due to the absence of the accessory chromosome, as Miss Wallace does in the spider. The only probable explanation, it seems to me, is imperfect mitosis. Cases where more or less chromatin is left behind in the cytoplasm, especially in the first spermatocyte mitosis, are very common, and such cases as those shown in figures 149 and 150 are not rare. The giant cells, so far as I have been able to trace them, do not develop into spermatozoa.

The most important points are :

(I) The presence of the element $x$ in the spermatogonia, closely associated with the nucleolus.

(2) The uneven number of chromatin elements in the metaphase of spermatogonial divisions.

(3) The connection of the element $x$ with the spireme up to the stage where the spireme segments to form the bivalent chromosomes.

(4) The varied character of the tetrads, showing the first spermatocyte division to be a reducing division in the sense that it separates whole chromosomes.

(5) The fact that the element $x$ fails to divide in the first maturation division, does divide in the second, but can not be traced beyond the equatorial plate of the latter mitosis.

(6) The similarity of all the normal spermatids, though one-half of them must contain the element $x$, the other half not.

(7) The varying and often large number of degenerate spermatozoa. 
An attempt was made to determine the somatic number of chromosomes. The dividing cells of the follicles of young eggs seemed to afford the most favorable material, but even here there was so much overlapping of the ends of the chromosomes that it was impossible to be absolutely certain of the number. In the two most favorable cases 23 were counted (fig. 94). This differs from McClung's count for similar cases among the Orthoptera, and Sutton's for Brachystola magna. The eggs have so far resisted all efforts to learn what part the odd chromosome may play in fertilization.

\section{Tenebrio molitor.}

In the metaphase of all spermatogonial mitoses where it was possible to count accurately, 20 chromosomes were found, ig large ones of approximately equal size, and I small spherical one (figs. I69, I70). There is nothing in the resting nucleus of the spermatogonia which would suggest either a nucleolus or an accessory chromosome. The chromatin stains well during the whole growth period of the spermatocytes, but it is impossible to separate the period into so definite stages as in most other forms.

In the youngest spermatocytes one finds occasionally a cyst containing cells with nuclei like those of figures 171 and 172 , indicating that a brief "synapsis" or condensation stage occurs at the close of the last spermatogonial mitosis. During the greater part of the period the chromatin forms a heavy, irregular, and often segmented spireme (figs. 173, 174). Shortly before the first maturation division, such split segments as appear in figure 175 are sometimes found; some of these simulate tetrads with slender connecting bands between the paired elements. Again, one finds a few cases like figure 176 , where the spireme is segmented into bivalent chromosomes, each component showing a longitudinal split. This figure also shows the small chromosome. Usually, however, the irregular and much tangled spireme (figs. 173, 174) condenses into a heavy segmented band variously disposed in the nucleus (fig. 177). This band soon separates into the bivalent chromosomes shown in figures 178 and 179 , giving 9 symmetrical pairs and I unsymmetrical one (fig. I79s) composed of the small chromosome and a much larger mate. In the prophase of the spindle, in rare cases, some of the chromosomes are longitudinally split and transversely constricted, forming tetrads (fig. I8o), but more often they appear as in figure $18 \mathrm{r}$. The unequal pair appears in each figure at $s$. In the metaphase (fig. 182) it is the last to come into the equatorial plate, possibly because of its lack of symmetry. The smaller component of this pair is always directed toward the equator of the 
spindle. Figure ${ }^{8} 83$ shows a small tangential section of a spindle in metaphase, containing the unequal pair and one equal pair. In figure 184 a polar view of a metaphase is shown, the unequal pair, which was somewhat below the others, being indicated by stippling. Figures I $84 a$ and I 85 show that the unequal components of the unsymmetrical pair, as well as the equal components of the symmetrical pairs, are separated in metakinesis, making this clearly a reduction division. Two polar plates are shown in figures I 86 and I 87 , one containing ro equal elements, the other 9 equal ones and I small one. The telophase is shown in figure 188 . There is no resting stage, but the new spindle is formed from the remains of the old one, and the spindle-shaped mass of chromatin seen in figure 188 either passes into the center of the new spindle or becomes enveloped by it. The double chromosomes separate as in figures 189 and 190 . Figure I90 shows the small dyad, and figure 189 an aberrant one which may be its mate. The spindle in both divisions is peculiar in having outside of the spindle proper a dense mass of fibers which, in osmic material, stain deeply with iron hæmatoxylin. These fibers are shown in all the figures from 174 to 196 . Figures 191 and 192 are equatorial plates of the two kinds of spermatocytes of the second order, figure I9I showing the small chromosome. An early anaphase appears in figures 193 and 194, which show both the small and larger chromosomes in metakinesis. Figure 195 is a later anaphase containing the divided small chromosome. In figure 196 are shown the two polar plates of a spindle corresponding to that of figure 195, and in figure 197 the polar plates of a spindle in which ro equal chromosomes have been divided. In Tenebrio molitor the spermatids are therefore certainly of two distinct kinds, so far as the chromatin content is concerned.

In most of the young spermatids, after the nuclear membrane has formed, there appears an isolated chromatin element, which corresponds fairly well to the large or to the small component of the unsymmetrical pair, separated in the first mitosis and divided in the second. The clear portion of the nucleus containing this isolated element is at first turned toward the spindle-remains (fig. 198), but before the tail appears either the whole nucleus or its contents have rotated $180^{\circ}$ (fig. I99). Various stages in the development of the spermatid are seen in figures 200 to 203 . The clear region and the isolated element finally disappear (fig. 202 b), and the chromatin breaks up into coarser and then into finer granules within the sperm-head. In the later stages the centrosome is clearly seen at the base of the head (fig. 203).

In order to determine, if possible, the value of the unsymmetrical pair of chromatin elements, very young ovaries and ovaries with egg- 
tubes were sectioned and the chromosomes counted in the dividing cells of the egg-follicle ( $q$ somatic cells), and in dividing oögonia. In both cases 20 large chromosomes were found. Figure 207 is the equatorial plate from a female somatic cell of a young egg-follicle. Figure $208 a$ and $b$ shows two sections of an oögonium in the prophase of mitosis. In order to determine the number and character of the chromosomes in the male somatic cells, several male pupæ were sectioned. As in the spermatogonia, I9 large chromosomes and I small one were found. Figure 204 shows the equatorial plate of a dividing male somatic cell, and figures 205 to 206 are daughter plates from a similar cell. (Three large chromosomes of the plate shown in figure 206 are in another section.)

From these facts it appears that the egg-pronucleus must in all cases contain ro large chromosomes, while the spermatozoön in fertilization brings into the egg either ro large ones or 9 large ones and I small one. Since the somatic cells of the female contain 20 large chromosomes, while those of the male contain I9 large ones and I small one, this seems to be a clear case of sex-determination, not by an accessory chromosome, but by a definite difference in the character of the elements of one pair of chromosomes of the spermatocytes of the first order, the spermatozoa which contain the small chromosome determining the male sex, while those that contain ro chromosomes of equal size determine the female sex. This result suggests that there may be in many cases some intrinsic difference affecting sex, in the character of the chromatin of one-half of the spermatozoa, though it may not usually be indicated by such an external difference in form or size of the chromosomes as in Tenebrio. It is important that related forms should be studied in order to ascertain whether the same chromatic conditions prevail in other species of this genus or possibly in the Coleoptera in general.*

\section{Aphis oenotherae.}

The spermatogensis of Aphis has been fully described in another paper and will merely be briefly summarized here for the purpose of comparison with other forms.

The spermatogonia contain a large nucleolus, which gradually disappears in the prophases of mitosis (plate vII, figs. 209-2II). The youngest spermatocytes closely resemble the spermatogonia (fig. 212). There is no bouquet stage and no such marked spireme stage as in

\footnotetext{
* Prof. E. B. Wilson has recently found a similar dimorphism in the spermatozoa of Lygaus and other of the Hemiftera heteroptera.
} 
many other insects. The true synapsis occurs, as shown in figure $2 \mathrm{I}_{3}$, by pairing of like chromosomes side by side. This conjugation of like chromosomes is followed by a stage in which they are massed together at one side of the nucleus (fig. 214). In these latter stages the nucleolus has entirely faded out and nothing suggesting an accessory chromosome is present. Figures 215 and 216 are equatorial plates of the first spermatocyte mitosis. There are 5 chromosomes of different sizes and shapes, and figure 216 shows each one double. The first division of the chromosomes, though apparently longitudinal, is evidently a separation of the elements paired in a preceding stage, and is therefore a reducing division.

The anaphase of the same mitosis is shown in figures 217 and 218 ; it is peculiar in that one chromosome always divides more slowly than the others, the two elements hanging together at one end. In figure 2 I9 are sister spermatocytes of the second order, the "lagging " chromosomes still connected. The second maturation division is seen in metaphase in figure 220 and in anaphase in figure 221. Figure 222 shows a young spermatid, the five chromosomes still preserving their characteristic form. Figure 223 is the equatorial plate of the first maturation division of the winter egg, showing the same form and size relations of the chromosomes as in the spermatocyte divisions. Figures 224 and 225 are equatorial plates of a polar spindle (fig. 224) and of a segmentation spindle (fig. 225) of the parthenogenetic egg, where ro chromosomes are present, 2 of each of the sizes found in the sexual germ cells.

So far as an accessory chromosome or any other visible evidence of a sex determinant are concerned, the results are entirely negative. The conditions shown do, however, support Mendel's conception of the "purity of the germ-cells," and also afford evidence in favor of Boveri's theory of the individuality of the chromosomes.

\section{Sagitta bipunctata.}

In connection with these insect forms it is of interest to find in the spermatogenesis of Sagitta a body which stains like chromatin and behaves somewhat like the accessory chromosome. It is found in all resting stages of the spermatogonia, closely applied to the nuclear membrane (fig. 226). It divides before each spermatogonial mitosis (fig. 227) and, though not often discernible in the spindle, appears in the next generation. Figure 228 is the last spermatogonial mitosis, and figure 229 shows the element $x$, and the chromosomes paired at one pole of the spindle. During the various phases of the growth stage (figs. 230-232) the element $x$ is again applied to the nuclear mem- 
brane. In the prophase of the first maturation division this element divides (figs. 233-234), and in metakinesis the two elements are found in various positions with regard to the spindle (figs. 235-237), often as conspicuous as in these figures, but sometimes concealed among the chromosomes. Before the spindle for the second division forms, this element divides again and one of the products goes into each spermatid (figs. 238-24I).

As Sagitta is hermaphrodite, there would appear to be no question of sex determination by any special chromatic element. The size of the element $x$, its evident chromatic nature, its division before each mitosis, and its presence in mitosis and in the spermatids, with the same staining qualities as in the previous rest stages, certainly indicate some important function, either in the whole process of spermatogenesis or in the formation of the sperm-head, of which it finally becomes a part. In Sagitta this element certainly can not be regarded as a specialized spermatogonial chromosome, or as chromatin rejected from the spireme. No such element is present in the ovogenesis of Sagitta (Stevens, '03), nor has any been detected in connection with fertilization. It is certain that none is present in the first segmentation spindle of the egg.

\section{GENERAL DISCUSSION.}

\section{THE "ACCESSORY CHROMOSOME."}

The literature bearing on the "accessory chromosome" of McClung, the "small chromosomes" of Paulmier, and the "chromatin nucleoli" of Montgomery has been fully discussed by McClung in the paper entitled, "The accessory chromosome-sex determinant?" ('02), and will therefore be considered here only in its relation to the several forms studied. The present status of the question has been well summarized more recently by Montgomery under the heading "Heterochromosomes" in the paper, "Some observations and considerations upon the maturation phenomena of the germ cells."

Three theories as to the function of the "heterochromosomes" have been advanced: (I) That of McClung that they are sex-determinants, since in the forms which he has examined these chromatin bodies occur in only one-half of the spermatozoa, and the sex-character is the only character which divides the individuals of a species into two approximately equal groups. (2) That of Paulmier and Montgomery that they are degenerating chromatin. Montgomery regards them as "chromosomes that are in the process of disappear- 
ance in the evolution of a higher to a lower chromosome number." (3) That of Miss Wallace, who suggests that in the spider only the one out of each four spermatids which contains the accessory chromosome is capable of developing into a functional spermatozoön, while the other three degenerate, as do the polar bodies given off by the egg. McClung is inclined to believe that the accessory chromosome is an element common to all of the male reproductive cells of Arthropods, and probably to vertebrate spermatocytes as well ('O2).

Of the insects considered in this paper Aphis and Termopsis have no "accessory chromosome" or "heterochromosome" of any kind. The fact that no males develop from the fertilized eggs of Aphis might be offered as a reason for its absence, but such an argument would not apply to Termopsis. The sex-character may indeed be represented in the chromatin of some one of the pairs of paternal and maternal chromosomes of the spermatocytes, but there is no evident peculiarity by which one-half of the spermatozoa can be said to be different from the other half. As to McClung's statement ('O2) "that if there is a cross-division of the chromosomes in the maturation mitosis, there must be two kinds of spermatozoa, regardless of the presence of the accessory chromosome," it appears to me that in a case like the aphid, where the paired elements of the five bivalent chromosomes are separated in the first maturation mitosis, there may be as many as seventeen kinds of spermatozoa instead of two. If, however, we suppose that the sex characters are segregated in the first maturation mitosis, there would, of course, be two equal classes of spermatozoa with reference to that character.

In Stenopelmatus the element $x$ in certain stages closely resembles the "accessory chromosome" of McClung, and especially that described by Baumgartner for Gryllus domesticus, but its origin and fate are different. It first appears attached to an end of the spireme in the growth stage of the young spermatocytes, where it is much smaller than in later growth stages. It gradually increases in size, is a conspicuous element in the first maturation spindle, goes into one of each pair of spermatocytes of the second order, and there degenerates during the rest stage between the two maturation mitoses. The whole history of this element suggests that it may be rejected chromatin analogous to that observed in the ovogenesis of many forms. In Sagitta, for example, a considerable quantity of chromatin granules is given off by the chromosomes and cast out into the cytoplasm near the close of ovogenesis (Stevens, 'O3). Rückert ('92) has described a similar casting out of chromatin material by the chromosomes of the oöcytes of Pristiurus. 
The spermatogenesis of Stenopelmatus, therefore, differs from that of the other Orthoptera which have been described in having ( $\mathrm{r}$ ) a larger number of chromosomes (46), (2) an even number in the spermatogonia, (3) an accessory chromatin structure in the spermatocytes of the first order, which disappears before the second maturation division.

In Blattella we have a typical "accessory chromosome," according to McClung. It appears (I) in all resting spermatogonia closely associated with a nucleolus, (2) in the spermatogonial mitoses as an odd chromatin element, making 23 in all, (3) in the growth stage of the spermatocytes connected with an end of the spireme and also with the nucleolus. It becomes separated from the other chromatin in the tetrad-stage, remains nucleolus-like in form, and later appears in the first maturation division either among the chromosomes or in a more or less aberrant position. It passes into one of each pair of spermatocytes of the second order, persists during the rest stage, appears in the second mitosis as a dyad and then divides, going into one-half of the spermatids. The spermatids, however, as in Stenopelmatus, all have the same appearance: each has in the center-not against the nuclear membrane-a small element that stains like chromatin. Occasionally a mass of chromatin is found outside the nucleus, but this is not constant enough to support the contention of Moore and Robinson ('05) that the "nucleolus" of the related form, Periplaneta americana, is fragmented and cast out into the cytoplasm. The spermatids all appear to develop equally well for some time, but as they approach maturity a varying proportion of them become degenerate. This can not, however, be due to absence of the accessory chromosome, as Miss Wallace supposes, in the spider; for in some follicles no degenerate spermatozoa are found, and in others more than half may be degenerate. All attempts to study fertilization stages of the egg have so far failed, and the chromosomes in the female somatic cells have not proved favorable for counting. Twenty-three have been counted in several cases, but there was always some chance of error. If 23 is the somatic number in both sexes, it must be maintained by union of sex-cells containing II and 12 chromosomes, respectively, the same unequal number occurring in the maturated eggs as in the sperm. Under such conditions it is difficult to see how the odd chromatin element of the spermatozoa can determine sex.

The brief description of the chromatin element $x$ in Sagitta, introduced here because it behaves like the accessory chromosome in many particulars, serves as an example of the occurrence of such an element in the spermatogenesis of a hermaphrodite form, where it can 
not possibly be conceived of as a sex determinant. In Sagitta it is known to be confined to the male germ-cells. No such element occurs in the ovogenesis, in the sperm nucleus in the egg, or in the first segmentation spindle. Its function must, therefore, be confined to the process of spermatogenesis.

From the standpoint of sex determination, we have in Tenebrio molitor the most interesting of the forms considered in this paper. In both somatic and germ cells of the two sexes there is a difference not in the number of chromatin elements, but in the size of one, which is very small in the male and of the same size as the other 19 in the female. The egg nuclei of the female must be alike so far as number and size of chromosomes are concerned, while it is absolutely certain that the spermatids are of two equal classes as to chromatin content of the nucleus-one-half of them have 9 large chromosomes and I small one, while the other half have ro large ones. Since the male somatic cells have I9 large and I small chromosome, while the female somatic cells have 20 large ones, it seems certain that an egg fertilized by a spermatozoön which contains the small chromosome must produce a male, while one fertilized by a spermatozoön containing ro chromosomes of equal size must produce a female. The small chromosome itself may not be a sex determinant, but the conditions in Tenebrio indicate that sex may in some cases be determined by a difference in the amount or quality of the chromatin in different spermatozoa. This is much the most suggestive part of the work, and it will be followed up by the study of related forms.

There appears to be so little uniformity as to the presence of the heterochromosomes, even in insects, and in their behavior when present, that further discussion of their probable function must be deferred until the spermatogenesis of many more forms has been, carefully worked out.

BryN MAWr College, May 15, rgo5. 


\section{BIBLIOGRAPHY.}

BAUMgartner, W. J.

'04. Some new evidences for the individuality of the chromosomes. Biol. Bull., vol. 8 , no. I

McClung. C. E.

'99. A peculiar nuclear element in the male reproductive cells of insects. Zool. Bull., vol. 2.

'00. The spermatocyte divisions of the Acrididæ. Kans. Univ. Quart., vol. 9, no. I.

'01. Notes on the accessory chromosomes. Anat. Anz., bd. 20, nos. 8 and 9 .

'02. The accessory chromosome-Sex-determinant? Biol. Bull., vol. 3, nos. I and 2.

' $02 \alpha$. The spermatocyte divisions of the Locustidæ. Kans. Univ. Quart., vol. I, no. 8 .

Montgomery, Thos. H., JR.

'01. A study of the chromosomes of the germ-cells of Metazoa. Trans. Amer. Phil. Soc., vol. 20.

' $01 \alpha$. Further studies on the chromosomes of the Hemifter $\alpha$ heterofter $\alpha$. Proc. Acad. Nat. Sci. Phila. rgor.

04. Some observations and considerations upon the maturation phenomena of the germ-cells. Biol. Bull., vol. 6, no. 3 .

MOORE, J. E. S., and Robinson, L. E.

'05. On the behavior of the nucleolus in the spermatogenesis of Periflaneta americana. Quart. Jour. of Mikr. Sci., n. s., no. I92 (vol. 48, part 4).

Paulmier, F. C.

'93. Chromatin reduction in the Hemiptera. Anat. Anz., vol, I4.

'99. The spermatogenesis of Anasa tristis. Journ. of Morph., vol. I5.

RUCKERT, J.

'92. Zur. Entwickelungsgeschichte des Ovarialeies bei Selachiern. Anat. Anz., vol. 7 , no. 4 and 5 .

DE SINÉTY, R.

'01. Recherches sur la biologie et l'anatomie des phasms. La Cellule, vol. I9.

Stevens, N. M.

'03. On the ovogenesis and spermatogenesis of Sagitta bipunctata. Zool. Jahrb., vol. I8.

Sutton, W. S.

'02. On the morphology of the chromosome group in Brachystola magna. Biol. Bull., vol. 4, no. r.

'03. The Chromosomes in heredity. Biol. Bull., vol, 4, no. 5.

Wallace, L, B.

'00. The accessory chromosome in the spider. Anat. Anz., vol. I8.

'05. The spermatogenesis of the spider. Biol. Bull., vol. 8 , no. 3 .

WiLcox, E. V.

'95. Spermatogenesis of Caloptenus femur-rubrum and Cicada tibicen. Bull. Mus. Comp. Zool. Harvard Univ., vol. 27.

'96. Further studies on the spermatogenesis of Caloptenus femur-rubrum. Bull. Mus. Comp. Zool. Harvard Univ., vol. 29.

'97. Chromatic tetrads. Anat. Anz., vol. I4.

'01. Longitudinal and transverse division of chromosomes. Anat. Anz., vol. I9, no. 13 . 
[The figures of plates I-VI were all drawn with Zeiss oil-immersion $2 \mathrm{~mm}$., cc. I2, and have been reduced one-third; those of plate vil with oc. 8 , not reduced.]

\section{Plate I.}

Termopsis angusticollis.

FIGS. I-3. Resting nuclei of spermatogonia, showing division of nucleolus.

4. Equatorial plate of spermatogonial mitosis, 52 chromosomes.

5-6. Young spermatocytes, showing division of nucleolus.

7. First maturation spindle, and two nuclei (6 and 8$)$ in same cyst.

8-10. Skein-stage-so-called synapsis-stage.

II-I4. Bouquet-stage, showing two nucleoli, centrosome $(c)$ in fig. II, and loops made up of fine, then coarser granules.

15-17. Stage following preceding; loops straightened out and extending in various directions through nucleus.

18. $a$, Chromosomes much shortened and longitudinally split; $b$, chromosomes contracted to form diamond-shaped figures.

19. Stage between $18 a$ and $18 b$.

20. Stage between 19 and $18 b$.

21. Stage similar to $18 a$, one chromosome in double diamond form.

22. First maturation spindle in metaphase, chromosomes in single and double diamond shapes.

23. Chromosome in single diamond or tetrad form, as they usually come into the spindle.

24. Double diamond-form assumed before metakinesis.

25. The 26 chromosomes of an early metaphase.

26. First maturation spindle in metakinesis.

27. Equatorial plate of first maturation spindle in metakinesis.

28. Another spindle, showing three granules which are probably remains of nucleoli.

29. Anaphase of first maturation mitosis, one centrosome divided.

30. Late anaphase.

3I-32. Telophase, exceptional cases of division of the cell.

33-36. Partial rest stage between first and second maturation divisions, two nucleoli present. Chromosomes in fig. 36 in form of double diamonds ready for metakinesis.

37-38. Second maturation spindle in metaphase.

39. Equatorial plate of second maturation spindle, 26 chromosomes.

40. Same in anaphase.

4I. Four spermatid nuclei in one cell, each nucleus containing one nucleolus.

42. A later stage, showing elongation of nuclei, centrosome and sphere at posterior end.

43-45. Later stages in the development of the spermatozoa, nucleolus grows gradually smaller. 


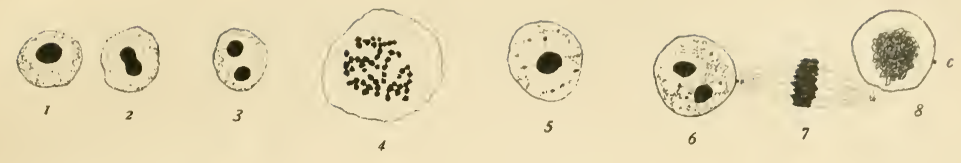

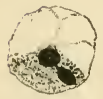

9
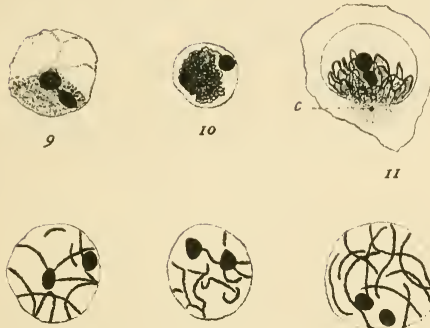

I5

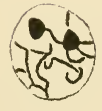

16
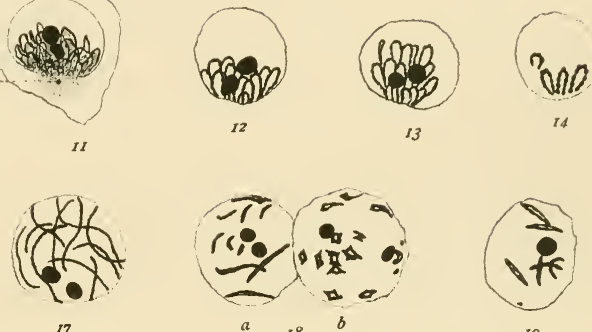

$\left(\begin{array}{lll}0 & 0 & 0 \\ 0 & 0 \\ 0 & 0 \\ 0 & 0 & 0\end{array}\right)$

20
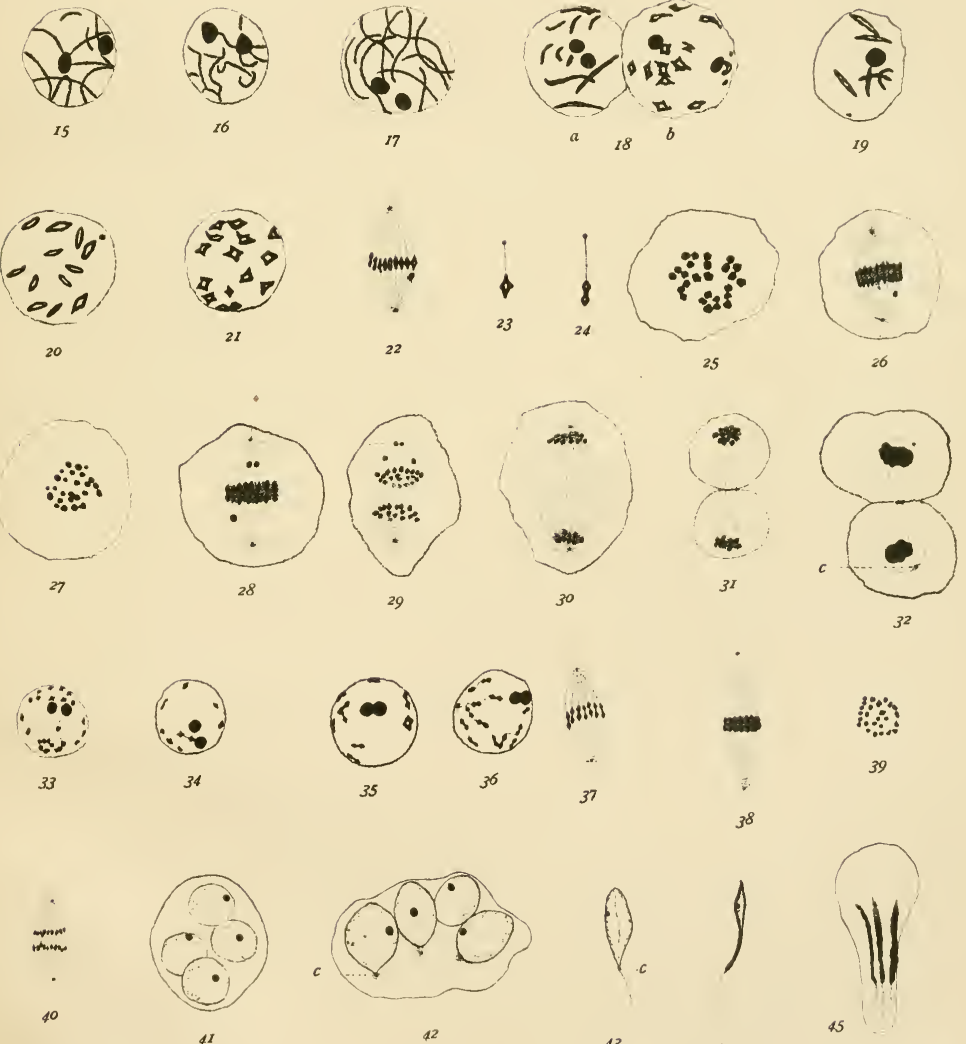

s.

$4 I$

N. M. 8. del.

TERMOPSIS ANGUSTICOLLIS. 




\section{Plate II.}

\section{Stenopelmatus.}

FIGS. 46-47. Nuclei of spermatogonia, showing 2 and 3 nucleoli $(n)$.

48-49. Prophase of spermatogonial mitosis, showing two exceptionally large chromosomes of equal length.

50. Equatorial plate of spermatogonial mitosis, 46 chromosomes.

5I-54. Spermatocytes in spireme stage, nucleus containing a nucleolus $(n)$, and a chromatin element $(x)$, which is attached to one end of spireme and gradually increases in size during growth stage of spermatocytes.

55. Spireme longitudinally split and showing the beginning of cross formation.

56. Spireme segmented, tetrads forming.

57. One split segment and a part of another connected by bands of linin.

58. More open cross and diamond forms; element $x$ conspicuous.

59-60. More contracted cross and diamond-shaped tetrads; linin bands shown in 60 , where element $x$ is also present.

6I. Different forms assumed by element $x$ during tetrad stage (figs. 56-60)

62-63. Diamond-shaped and contracted cross-shaped tetrads from metaphase of first maturation mitosis, showing linin connections.

64. Diamond-shaped tetrad with spindle-fibers attached; $a-a$, probably halves of one univalent chromosome; $b-b$, halves of the other.

65. Dyad from anaphase of first maturation mitosis.

66-67. Metaphase of first maturation spindle, showing element $x$ in different positions.

68. Late anaphase of same.

69-7o. Equatorial plate of first maturation spindle, 23 chromosomes and element $x$ below, in fig. 69 .

7I. Chromatin massed at poles of spindle; element $x$ isolated at one pole.

72-73. Two resting spermatocytes of the second order, one containing element $x$, the other not.

74-76. Successive stages of breaking down of element $x$.

77. Prophase of second division; dyads evident, but no sign of $x$ in this or following stages.

78. Second spermatocyte division-metakinesis.

79. Same; late anaphase. 

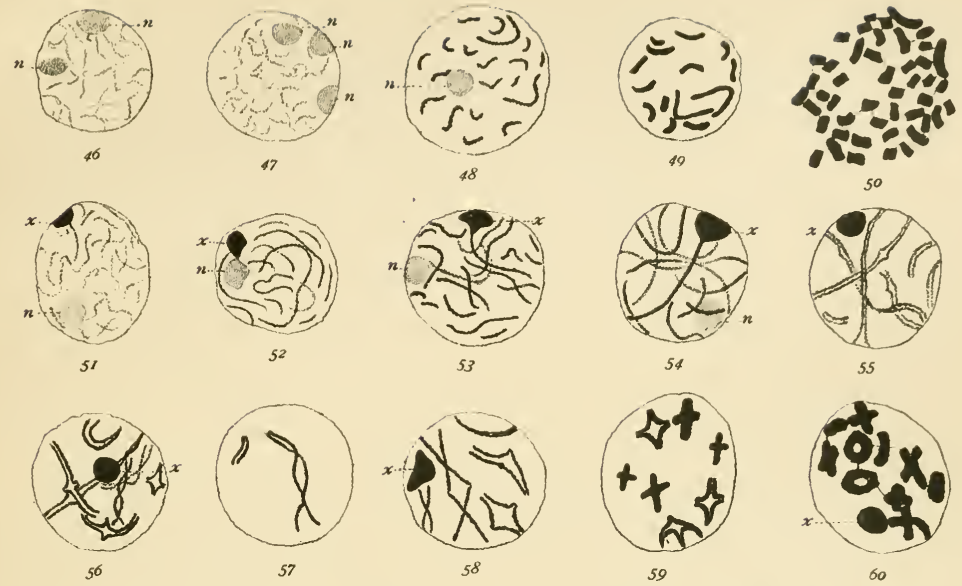

810
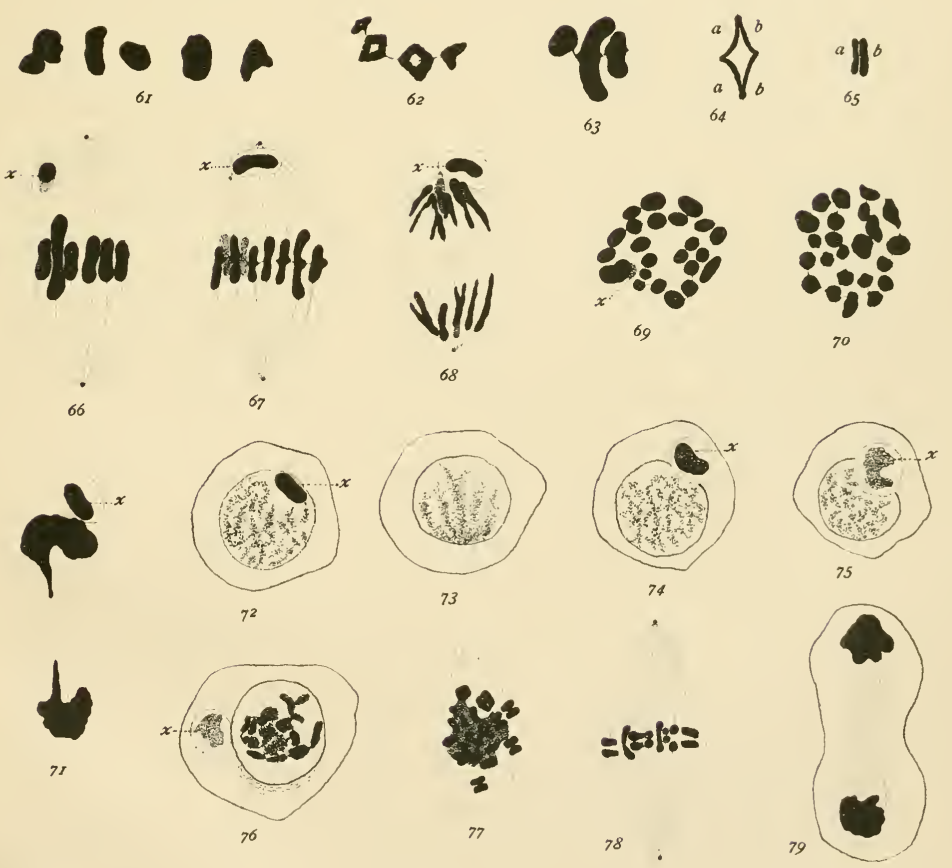




\section{Plate III. \\ Stenopelmatus.}

Fig. 8o. Telophase of second maturation mitosis.

8I. Young spermatid, showing spindle-remains at $s$.

82. Spermatid showing a conspicuous chromatin element in nucleus, and spindle-remains $(s)$ elongated.

83. Spermatid, showing centrosome $(c)$ and divided spindle-remains ( $s$ and $a$ ).

84. Older spermatid, showing centrosome (c), axial fiber of tail, and spindleremains $(s)$.

85. Spermatid, showing acrosome material (a) migrating to side of nucleus opposite centrosome.

86. Slightly older spermatid.

87. Later stage of spermatid, showing condensed chromatin, elongated centrosome $(c)$, acrosome material $(a)$, and spindle-remains $(s)$.

88-89. Older spermatids, showing formation of acrosome $(a)$ and middle piece $(m)$. 90-92. More advanced stages.

93. Mature spermatozöon.

\section{Blattella germanica.}

FiG. 94. Somatic cell from egg follicle, 23 chromosomes.

95. Spermatogonium, showing chromatin element $(x)$ associated with a nucleolus $(n)$.

96. Same, prophase of mitosis.

97. Equatorial plate of spermatogonial mitosis, 23 chromatin elements.

98. Young spermatocyte, showing centrosome $(c)$ and $U$-shaped element $(x)$.

99. Young spermatocyte, element $x$ attached to one end of a long, fine spireme.

I00. Coarser spireme stage.

IOI-IO3. Bouquet stage.

104-105. Later spireme stage.

106. Various forms assumed by the combined nucleolus and element $x$; last figure from a giant cell.

107. Segmenting spireme.

108. Similar stage to fig. I07, one chromosome longitudinally split; element $x$ present. 

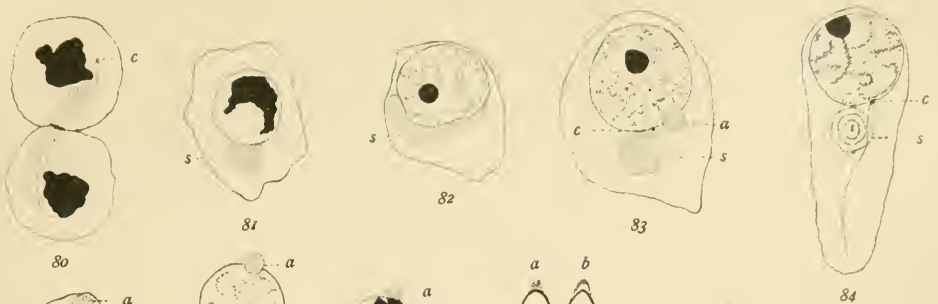

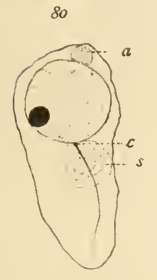

85
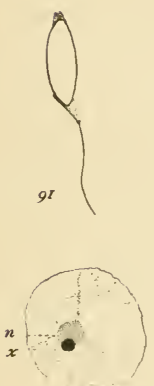

95

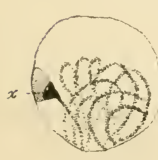

roo

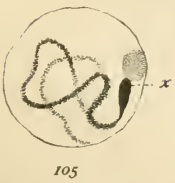

N. M. S. del.

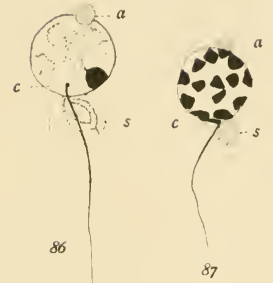

87

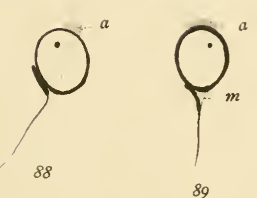

89
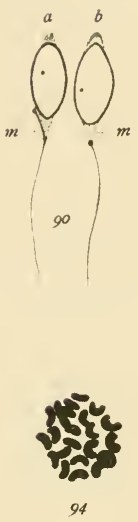
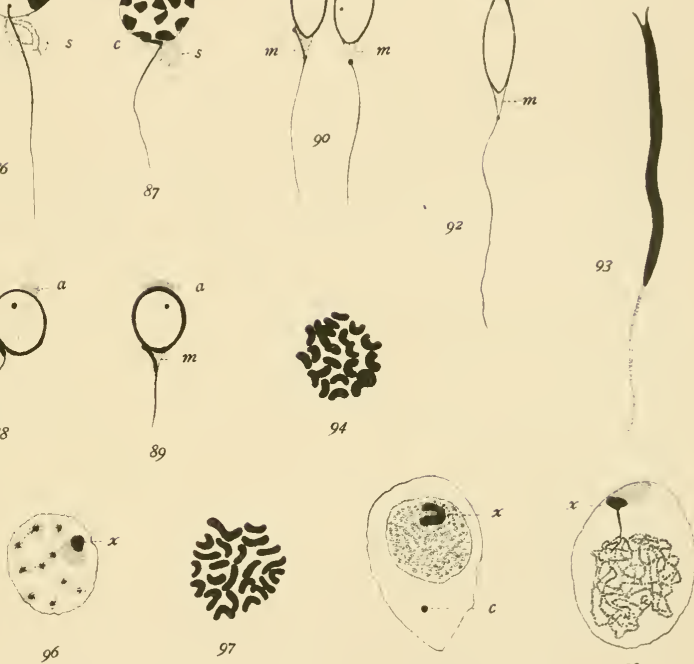

98

99

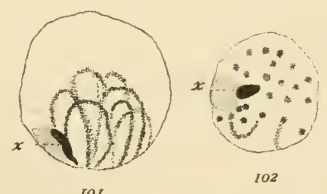

IOI
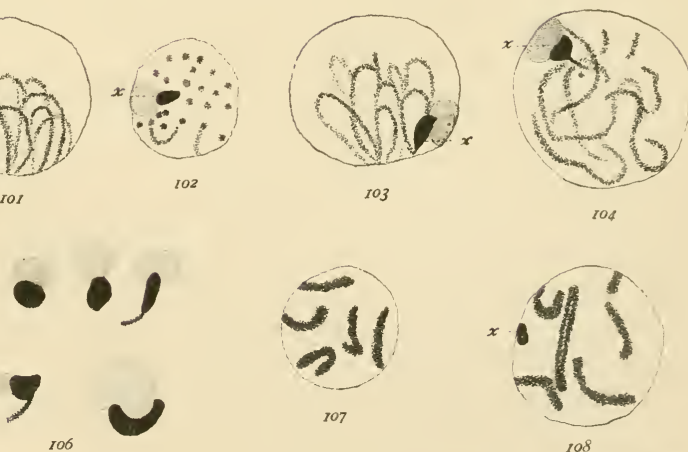

STENOPELMATUS-BLATTELLA GERMANICA. 


Plate IV.

Blattella germanica.

FIG. I09. Similar stage to figs. 107 and 108; chromosomes U-shaped and not longitudinally split; two centrosomes present $(c)$.

IIo. Longitudinally split chromosomes.

III-II3. Various stages in formation of cross-shaped tetrads.

II4-II7. Bent rods, $U$-shapes, split rings, pairs of rods, and rod-shaped tetrads (II6), which are equivalent to the crosses of figs. II2-II3.

I 18 -122. Metaphase of first maturation division, showing the element $x$ in various positions.

123-127. First maturation spindle in metaphase.

I28. Same in anaphase.

I29-132. Late anaphase, showing element $x$ double in 129, and a lagging tetrad in 130 .

I33. Telophase, with the element $x$ in one daughter cell.

I34-136. Prophase of second maturation mitosis, showing dyads and element $x$. 

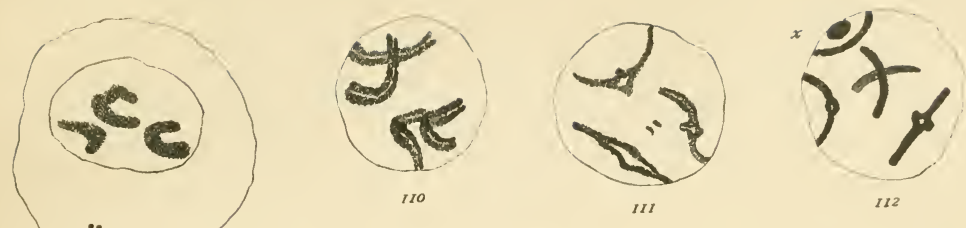

(113)

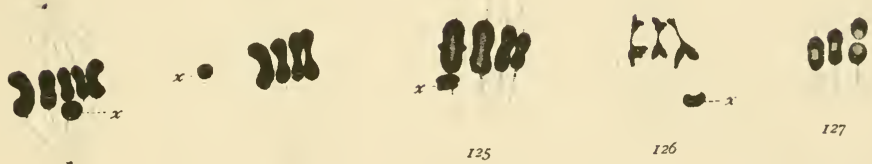

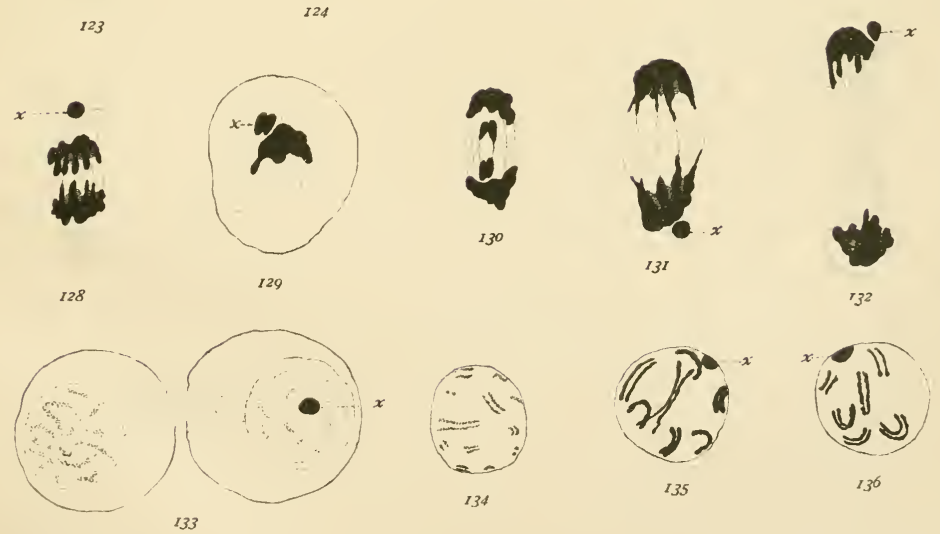




Plate V.

Blattella germanica.

FIGS. 137-14I. Dyads contracting for second maturation mitosis.

142. Equatorial plate of second maturation spindle, containing II chromosomes.

143-I44. Same, with II chromosomes and the element $x$.

I45-I 47. Sections of second maturation spindles; element $x$ dividing in I46 and 147.

I48. Telophase of second mitosis.

149. Telophase of second mitosis, showing masses of chromatin left behind in cytoplasm.

I50. Spermatid with extranuclear chromatin $(a)$.

15I. Similar stage; different view of spindle-remains $(s)$ and of chromatin element $\left(x_{2}\right)$

I52-153. Spermatid with divided spindle-substance and the corresponding double-tailed form.

154-155. Stages between 156 and 158 .

156-157. Older spermatids than I5I, showing spindle-remains $(s)$ and centrosome $(c)$.

158-160. Later stages in development of sperm-head.

I6r. Ripe spermatozoön.

I62-168. Degenerate spermatids and spermatozoa. 


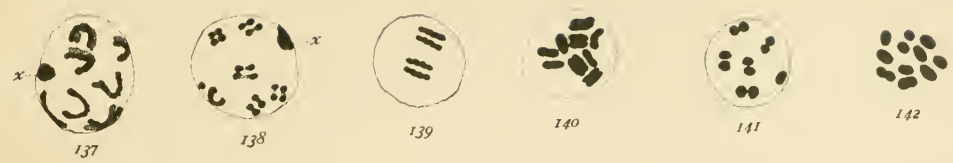

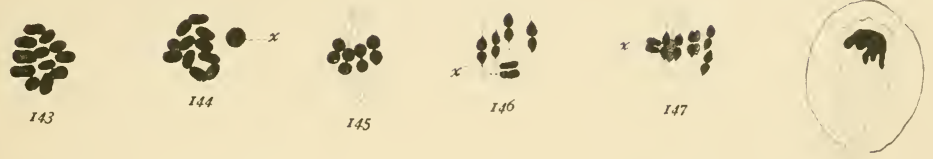
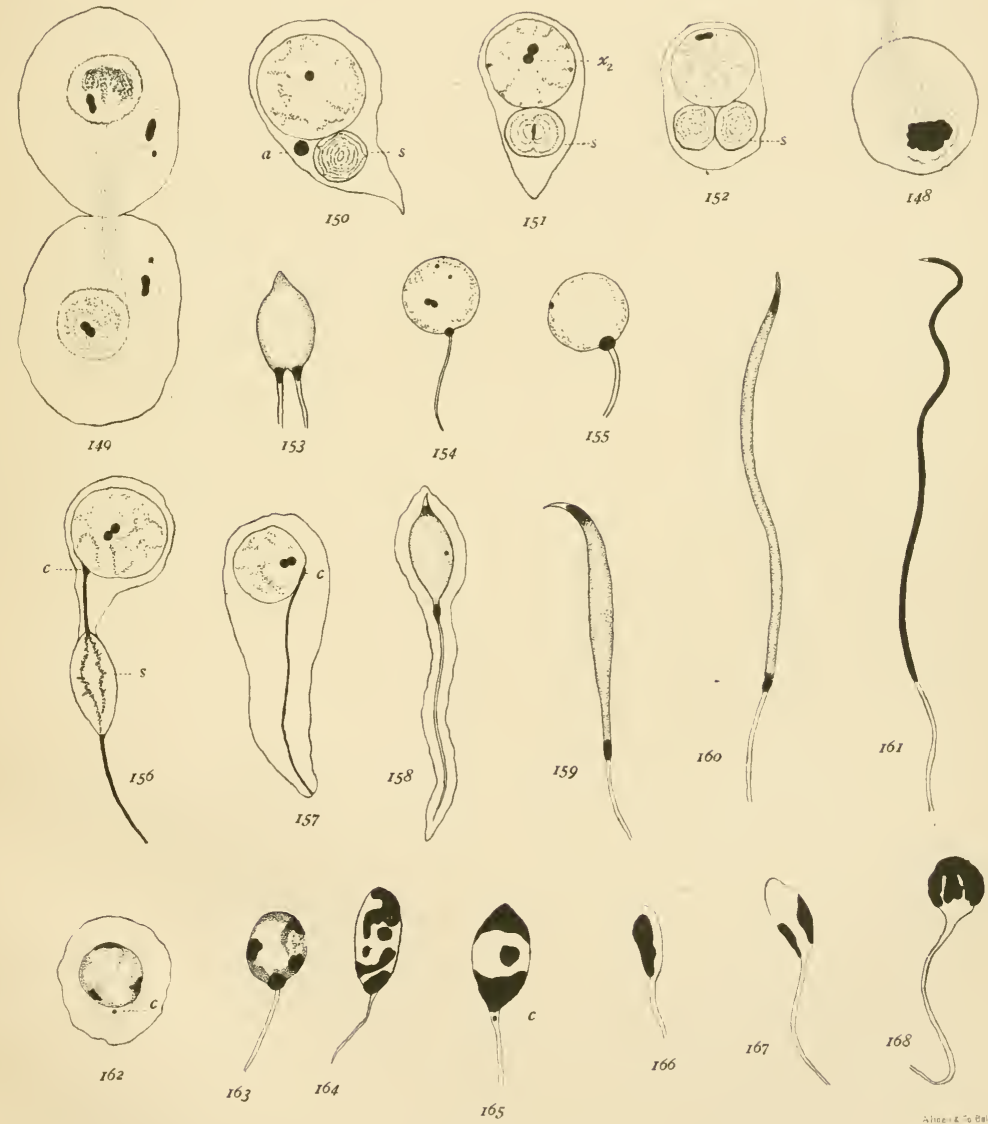

N. M. S. del.

BLATTELLA GERMANICA. 




\section{Plate VI. \\ Tenebrio molitor.}

FIGs. I69-70. Equatorial plates of spermatogonial mitosis, showing ig large and I small chromosome.

I7I-I75. Condensation stage, bouquet stage, spireme stage, and rather rare tetrad stage of young spermatocyte.

I76. Bivalent chromosomes, with longitudinal split; small chromosome shown at $s$.

177. Bivalent chromosomes condensed into a close spireme.

I78-I79. Bivalent chromosomes separating for mitosis. The unsymmetrical pair shown in fig. I79.

I80. Prophase of first maturation mitosis, showing the unsymmetrical pair and the tetrad nature of the symmetrical pairs.

I8I. Prophase of same mitosis, showing symmetrical and unsymmetrical pairs, as in figs. I78 and I79.

182. Metaphase, unsymmetrical pair out of the equatorial plane.

183. Tangential section of a spindle in metaphase, showing the unsymmetrical pair and one symmetrical pair.

I84. Equatorial plate of same mitosis, Io chromosomes.

I84a. Early anaphase, showing separation of the elements of the unsymmetrical pair.

185. Later anaphase.

I86. Polar plate, showing 9 large and I small chromosome.

187. Polar plate, showing 10 large chromosomes.

188. Condensation stage between the two maturation divisions.

I89-rgo. Prophase of second maturation division, fig. I 89 showing ro equal dyads, and fig. I90, showing 9 equal and I small dyad.

I9I. Equatorial plate, showing I small chromosome and 9 large ones.

I92. Equatorial plate, showing Io large chromosomes.

I93-I94. Tangential sections of spindle in metakinesis.

195. Anaphase of same mitosis.

I96. Polar plates of a spindle, showing in each I small chromosome and 9 large ones.

197. Polar plates of another spindle, ro large chromosomes in each.

198. Young spermatid, showing isolated small chromosome.

199. Young spermatid, showing isolated large chromosome and rotation of nuclear contents.

200-202a, b. Older spermatids.

203. Sperm-heads, showing centrosome and granular chromatin.

204. Equatorial plate from dividing somatic cell of male pupa, showing I9 large and I small chromosome.

205-206. Daughter plates of a similar spindle, showing small chromosome in each; three of the large chromosomes missing in 206.

207. Equatorial plate of a dividing cell of follicle of a young egg, showing 20 large chromosomes.

208. Prophase of mitosis in a young oögonium, showing 20 large chromosomes in two sections, $a$ and $b$. 


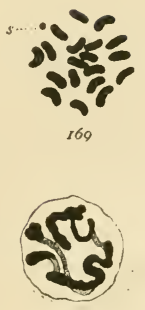

I74

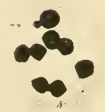

179

$\therefore$

184

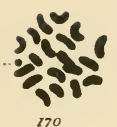

170

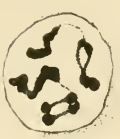

I75

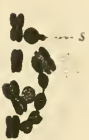

180

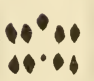

$184 a$
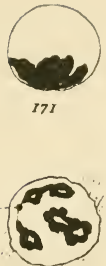

$I 76$

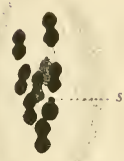

ISI
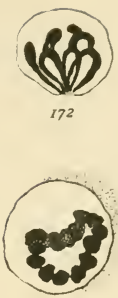

177

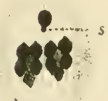

182

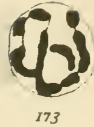

$\underbrace{203}_{178}$

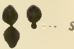

183
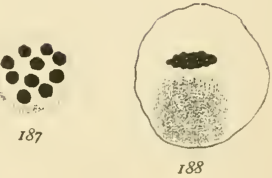

I 85

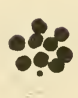

186

187
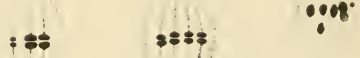

๑.?

193

195
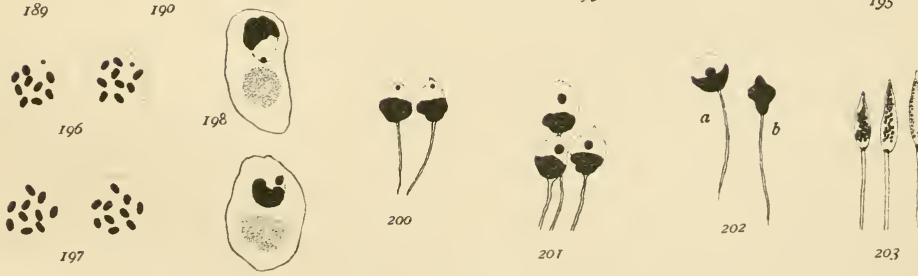

$I 99$
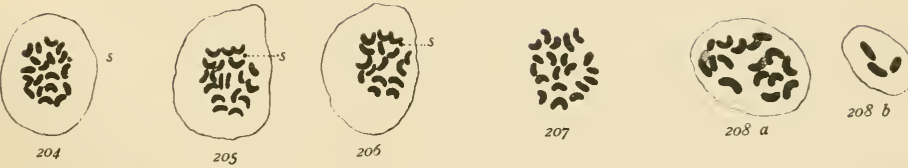




\section{PIATE VII. \\ Apliis oenotherae.}

Fig. 209. Spermatogonium.

210-21r. Spcrmatogonia in prophase of mitosis.

212. Young spermatocyte of first order.

213. Spermatocytes of first order; conjugation of the chromosomes.

214. Condensation of chromatin-spermatocytes of first order immediately before mitosis.

215. Equatorial plate of first maturation division.

216. Same, side view, showing chromosomes double.

217-218. Anaphase of same mitosis.

219. Daughter spermatocytes of second order.

220. Equatorial plate of second maturation mitosis.

221. Anaphase of same.

222. Young spermatid.

223. Equatorial plate of first polar spindle of winter egg.

224. Equatorial plate of polar spindle of parthenogenetic egg.

225. Equatorial plate of segmentation spindle of parthenogenetic egg.

\section{Sagitta bifunctata.}

FrG. 226. Resting spermatogonia.

227. Prophase of spermatogonial mitosis.

228. Last spermatogonial mitosis, metakinesis.

229. Anaphase of same, showing synapsis of chromosomes at pole of spindle, and element $x$.

230. Resting spermatocyte of first order.

23r. Bouquet stage.

232. Later growth stage.

233. Prophase of first maturation mitosis, some of the chromosomes split longitudinally.

234. Later stage, chromosomes condensing and element $x$ dividing.

235-237. First maturation mitosis.

238. Division of element $x$ between the two maturation divisions.

239. Second maturation mitosis.

240. Anaphase of same, showing the element $x$ more deeply stained than the chromosomes.

247. Young spermatids; element $x$ still conspicuous. 


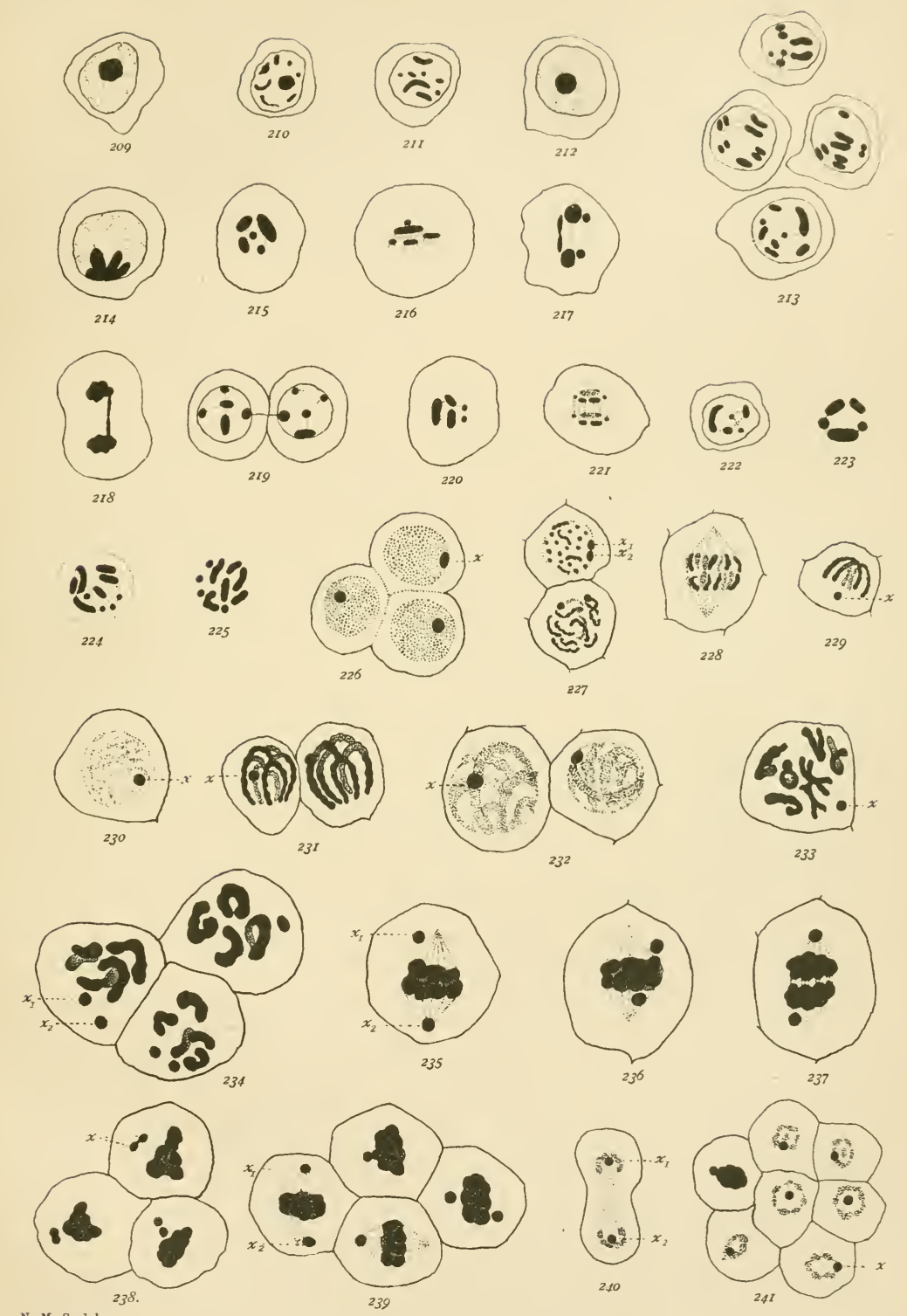

N. M. S. del.

APHIS CENOTHERA-SAGITTA BIPUNCTATA. 






. 